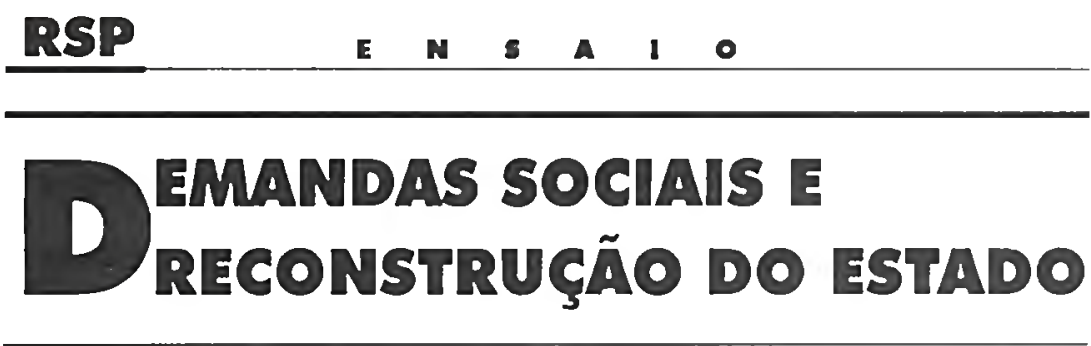

\title{
Indiana Pinheiro Fonseca Rodrigues
}

\section{Introdução}

0

$s$ sinais de mudanças profundas vêm hoje dos quatro quadrantes do globo terrestre $\mathrm{e}$ nos indicam periodos caracterizados como um tempo de maiores incertezas, desafios, conflitos, ameaças, mas ıambém esperanças. $O$ quadro que se configura neste final de século é de reformulação das instituições econômicas, sociais c políticas e, conseqüentementc, de delineamento de uma nova ordem institucional. $O$ avanço das comunicações tornou o mundo menor na medida em que tornou mais próximas as partes geograficamente distantes, trouxe maior transparência aos atos e fatos impondo novas demandas, ao mesmo tempo em que possibilitou a articulação e organização de novos grupos, principalmente de minorias marginalizadas. $\mathrm{O}$ abrandamento da dicotomia socialismo/ capitalismo empresta nova dimensão ao antagonismo ideológico e exige a redefinição do Fistado moderno.
Brasil tem vivido num estado mais ou menos permanente de crise, marcada por momentos de exarcebação, entremeados por outros momentos de relativa normalidade. Ademanda por mudanças é evidente. Uma reflexão sobre a formação do Estado brasileiro e sobre seu aparato político e burocrático, pode nos ajudar a entender os obstáculos que têm, recursivamente, impedido o governo de responder às demandas sociais. A convivência com dificuldades econômicas e financeiras, sem precedente, nas duas últimas décadas, tem induzido as autoridades a condicionar o social ao econômico e financeiro. A mais urgente das reformas é neconstruir nossas instituições, com base em valores, verdadeiramente democráticos, garantindo o direito de cidadania para toda a população.

Em meio a este turbilhāo de reformas o Brasil tem vivido num estado mais ou menos permanente de crise, marcada por momentos de exacerbação, entremeados por outros momentos de relativa normalidade. Esse estado prolongado de crise tem custado muito sacrificio a grande parcela da populaçāo, à qual tem sido debitada a 
conta, e que, com isso, está visivelmente amadurecendo. Um processo de mudança em curso é evidente e a consciência de cidadania já nāo está mais circunscrita a pequenos grupos, começa a aparecer como consciência coletiva. Essas mudanças impõem, sem sombra de dúvida, novas demandas sociais que terão de ser atendidas pelo Estado, sob o risco de enveredarmos para a violência que já é uma ameaça em nosso quotidiano urbano.

Embora o reconhecimen to de nossa dívida social seja hoje uma unanimidade, ainda estamos distantes de açōes concretas para iniciar o seu resgate. O que temos assistido, até aqui, são açōes de particulares - entre essas o melhor exemplo é a campanha contra a fome do Betinho - no esforço de minimizar os problemas. Enquanto essas ações são, clas próprias, indicadoras das mudanças que vêm ocorrendo na sociedade e representam a esperança dos tempos de transiçāo, a soluçāo efetiva dos problemas terá de vir dos poderes públicos constituídos, em última instância, os responsáveis pelo bem-estar social. Entendemos que a capacidade de resposta do Estado depende, diretamente, de sua reconsıruçāo, isto é, da reconstrução de nossas instituiçōes. $E$ importante enfatizar que essa recons- trução do Estado não pode ser entendida como reforma das estruturas administrativas, pois esse tipo de reforma já tivemos várias e já sabemos que não significam qualquer mudança efetiva'.

Detendo-nos em periodos mais recentes, a Nova República que se iniciou com Samey significava, no seu alvorecer, uma esperança de dias melhores e expressava, em seu discurso, a prioridade para o social. Desde que, de lá para cá nossos indicadores sociais só pioraram, cabe perguntar a que se deve toda aparente impotência dos governos para cumprir sua funçāo primeira que é o bem-estar social. Alguma reflexão sobre a formação do Estado brasileiro e sobre seu aparato político-burocrático, pode nos ajudar a entender os obstáculos que existem na arena politica e administrativa e que têm, recursivamente, impedido o governo de dar uma resposta às demandas sociais. A história da configuração do Estado e de sua relação com a sociedade, pode ser um instrumento útil para identificar os principais gargalos à institucionalizaçāo de valores democráticos em nosso país e apontar caminhos para a reconstrução do Estado. Na medida que essas demandas se tornam mais explícitas e se fazem ecoar com mais força, nossas instituiçōes dão sinais de esgotamento e

Sobre o assunto veja MOTTA, Paulo Roberto. Modernizaçào administrativa: propostas alternativas para o Estado latino-america no. Revista de Aclminist raçāo Pública. V.21, N.4, p.31-61, 1987. 
perda de legitimidade, o que representa um grande risco para todos os cidadāos.

Estado brasileiro e seu aparafo polífico-burocrático

sociedade brasileira nasceu e tomou forma sob a tutela do estado patrimonialista português, que por séculos administrou a colônia como um grande negócio da coroa portuguesa. Como mostra Faoro ${ }^{2}$, a organização política-administrativa do Estado português, juridicamente pensada, escrita e racionalizada, constitui uma corporação poderosa sustentada pelo estamento político burocrático. Com a transferência da corte de D. João VI em 1808 a tradição do estado patrimonialista finca suas raizes definitivas na en tão colônia. Isssa tradição, obviamente se mantêm intacta durante o primeiro e segundo reinado.

O advento da república trouxe mudanças de forma muito mais do que de processos, mesmo porque foi o resultado de um movimento da mesma elite que integrava o estamento político bu rocrático do
Estado. A simples tomada do poder, por uma facçāo dissidente, não poderia resultar numa mudança de comportamento da elite. Com a república nasce o sistema federativo, mas sem comprometer o poder da unidade central. O poder é assegurado principalmente por meio de acordos com chefes locais, acordos esses representados por privilégios e outras benesses, principalmente na forma de cargos públicos. Institucionaliza-se desta maneira a política clientelista. $A$ política dos governadores é outro mecanismo com o qual se fortalece o poder da clite dominante. Nas palavras de Iglésias ${ }^{3}$ "compōe-se deste modo a rede de interesses. E o apogeu das oligarquias. A descentralização, buscada como forma superior de atendimento dos direitos locais e individuais, acaba representando o máximo de compressāo das vontades, de exercício de dominação"(p.162).

Para avaliar o significado desta herança é bom lembrar algumas características do regime patrimonialista. Segundo Weber ${ }^{4}$, no estado patrimonial o príncipe organiza seu poder político acima das áreas extrapatrimoniais e su-

2 FAORO, Raimundo. Os donos do poder: formação do patronato politico brasileiro. 6.ed., Porto Alegre, Globo, 1984.

3 IGLESIAS, Francisco. Monentos democráticos na trajetória brasileira. In: Coleçāo Documentos Brasileiros. 196, Brasll, Sociedade Democrática. dirigida por Afonso Arinos de Melo Franco. Rio de Janeiro, José Olympio, 1985.

4 WEBER, Max. Economy and soclety. New York, Bedminster, 1968. 
jeitos políticos. Os sujeitos políticos, no estado patrimonial, são aqueles legitimamente governados pelo príncipe patrimonial. $O$ govemante patrimonial está ligado ao governado através de uma comunidade consensual que existe independente de sua força militar e que se fundamenta na crença de que o poder do govemante é legitimo desde que ele é tradicional. Usualmente, o govemante patrimonial mantém a seu lado o estrato económica e socialmente privilegiado, reservando para ele, com exclusividade, as posiçōes de liderança no exército, organizado como um corpo de unidades permanentes disciplinadas e treinadas. Essas posições são oferecidas, também, como oportunidades social e econômica em profissōes específicas na forma de cangos burocráticos.

E importante observar que a burocracia do regime patrimonial não é a burocracia racional c impessoal do estado modemo. Ao contrário, cla significa a apropriação do cango pelo seu ocupante. $\mathrm{O}$ que diferencia o burocrata patrimonial do burocrata do estado moderno, como definido no "tipo ideal" de Max Weber, é que para o primeiro o cargo público é objeto de seu interesse pessoal, ao contrário da ordem impessoal que caracteriza o cargo público para o segundos. No regime patrimonial o Estado não é uma estrutura hicrárquica piramidal, mas um amontoado de cargos definidos de acordo com os interesses da aristocracia subordinada. Diferente do feudalismo, que no processo de resistência à democracia liberal c ao capitalismo teve suas estruturas partidas e desapareceu, o regime patrimonial parece que tem sido capaz de sobreviver num processo de acomodação de novas instituiçōes dentro de suas velhas estruturas regeneradas.

A clite brasileira tem se mostrado extremamente hábil na sua capacidade de conservar os velhos padróes de relacionamen to entre o Fstado e a sociedade. Fazendo pequenas con cessōes e cooptando parcelas emergentes da classe média ela $\mathrm{tem}$ assegurado seu poder c scus privilégios. Lembrando, mais uma vez, as palavras de Iglésias "nossa história política não é uma linha reta vertical, afirmadora dos direitos públicos e individuais. de prerrogativas oficiais ou particulares. Ora é o Estado que avança, ora é o povo. Este é quase sempre contido, pois a máquina estatal, óbvia expressão dos in teresses do grupo dominante, está sempre alerta e consegue deter qualçuer arrancada mais audaciosa"(p.126). Essa forma de sustentação do po-

3 BUARQUE DE hOIANDA, Sérgio. Raizes do Brasil. 9.ed., Petrópolis, 1979. 
der tem efeitos perversos, entre cles o crescimen to racionalmente injustificável do aparelho politico burocrático e a deterioração dos mecan ismo democráticos de controle da sociedade. Nossa sociedade tem, preconceituosamente, associado controle a repressāo ${ }^{6} \mathrm{com}$ resultados nefastos para a grande maioria e cm contrapartida beneficio da elite, que com isso se dispensa da prestação de contas.

Até hoje as tentativas de modemização do listado ficaram circunscritas à adoção de técnicas modernas de administração. A crença subjacente é de que:

a) a incapacidade do listado de atender as necessidades básicas da sociedade é clevida à ineficiência de seu aparato burocrático;

b) o lsstado é ineficiente porque não foi capaz de implementar no sistema administrativo técnicas racionais e modernas de gestào; c

c) a modernizaçāo técnica do aparelho ad min istrativo garante a eficácia do sistema.

No entanto, essas reformas nāo tem logrado a eficácia do sistema e, até mesmo, pouco tem contribuido para um incremento da efi- ciência. A rajão é simples, de um lado importa-se técnicas desenvolvidas em sociedades que têm uma realidade politica social e económica diferente da nossa. Como diz. Crozier ${ }^{7}$, sistemas onganizacionais são respostas culturais para problemas que as pessoas confrontam na busca de suas metas coletivas. Por conseguinte a eficiência de técnicas administrativas é função de seu significado cultural. Por outro lado, as reformas do aparelho administrativo do Estado têm sido cuidadosas no sentido de preservar o poder de decisão sob controle da elite dominante, principalmente via um nú mero considerável de cargos reservados para pessoas de confiança.

Se a clite dominante mantém sua força e poxder no conservadorismo, a sociedade se moderniza. As mudanças, como no resto do mundo aceleradas, em especial, depois da segunda guerra mundial, resultaram em um descompasso entre a sociedade $\mathrm{e}$ as instituiçōes públicas. lisse descompasso nos a meaça, perigosamente, com uma crise de legitimidade de nossas instituições.

De um modo geral o termo instituição é entendido como abrangendo os aspectos, do comporta-

- Veja por exemplo MARTLS, Carlos Estevam. Governabilidade e Controles. Revista de Administração Ríblica, V.23, N.1, p.5-20, 1989.

7 CROZIER, Michel. The bureaucratic phenomenon. Chigago. The University of Chicago Press. 1964. 
mento social, regulados por normas e regras claramente definidas, facilmente reconhecidas e relativamente estáveis. Um conceito ainda mais abrangente nos diz que instituiçöes são tipificações recíprocas de açōes habituais de diversos tipos de atores sociais ${ }^{8}$. Como dizem Berger e Luckmann, esta definição enfatiza a reciprocidade das tipificaçōes institucionais e a tipicidade não apenas das açōes mas também dos atores nas instituiçōes, o que significa que as ações habituais tipificadas em instituições são compartilhadas pelos atores de um dado grupo social.

Quando as instituiçōes não corporificam valores e normas socialmente referendados elas perdem significado para a sociedade. Hoje o desgaste de nossas instituiçōes é patente. O congresso é talvez a mais desacreditada, por todos os mandos e desmandos que promove e pela corrupção desvendada, neste último ano, aos olhos pasmos da sociedade. $O$ executivo é visto como incompeten te na sua incapacidade de atender as necessidades e direitos básicos da população. As polícias por incapacidade material e humana e, em alguns casos, por corrupção são incapazes de conter a onda de violência e garantir a segurança dos cidadãos. $\Lambda$ justiça morosa $\mathrm{e}$ distante para o homem comum, lembra uma deusa no pedestal do olimpo, enquan to os mortais não têm a quem recorrer para fazer valer os seus direitos. Com isso impera a lei da selva onde os mais fortes exterminam os mais fracos.

\section{Ameaças e oportunidades}

quadro que temos hoje de nossas instituiçōes não é muito alentador, mas não é, também, de total desesperança. Não temos uma tradição democrática consolidada e talvez não a tenhamos porque nossas instituiçōes não incorporam, verdadeiramente, valores democráticos. O importante é que saibamos reconstruí-las com base em princípios que expressem as crenças e valores da sociedade, isto é, que corporifiquem as tipificações recíprocas de ações habituais dos atores sociais. Seria bom ter em mente a frase de Montesquicu que "o amor pela república, numa democracia, é o amor pela democracia; e que o amor pela democracia é o amor pela igualdade". Um país democrático nâo pode sustentar uma sociedade composta de privilegiados num extremo e marginalizados no outro. Num mundo de privilégios não tem lugar para a democracia. 


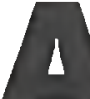

té hoje nossas instituições serviram, muito bem, aos interesses da elite dominante. Acontece que a julgar pelo nível de problemas que estão aí esperando soluçāo, este modelo de sociedade parece ter se exaurido. Se queremos ocupar, no mundo, um lugar de respeito, precisamos começar, com ungência, nossas reformas. Uma pergunta que se impõe é que concessões a clite está disposta a fazer. Seria uma utopia pensar que qualquer reforma fosse possível sem o concurso da elite que detêm o controle dos poderes constituidos.

As ameaças que pesam sobre nossas cabeças, se não formos capazes de iniciar essa reconstrução, sāo muitas e acredito bastante conhecidas. Contudo, talvez seja bom lembrarmos algumas, tais como, o crescimento da miséria, da fome, das doenças e epidemias, o aumento indiscriminado da violência, o descrédito do Estado até a perda total do controle c colapso do regime democrático, a incapacidade de produzirmos bens e serviços para competirmos no mercado internacional ou até mesmo para nosso proprio consumo. Sem querer ser pessimista o risco é mesmo o caos.

A con vivência com dificuldades econômicas e financeiras, sem precedente, nas duas últimas décadas, tcm induzido as autoridades a condicionar o social ao econômico e financeiro. Afogado na crise econômica $c$ financeira o país fi- cou anestesiado para os problemas sociais.

E verdade que a solução de muitos problemas depende de recursos financeiros. Não é, porém, menos verdade que muito pode ser feito independente da conjuntura econômica e financeira. 'Talvez fosse até mais conveniente invertermos a mão e reconhecermos que o progresso material consistente e duradouro é função da justiça e bem estar social.

As propostas de reforma da Constituição, de acordo com o que tem sido veiculado pela imprensa, retratam a preocupação preponderante com o econômico e o financeiro. O pressuposto subjacente é que é preciso equilibrar as finanças do Estado para viabilizar o bem-estar. Não estamos querendo dizer que equilibrar as finanças do Estado não é fundamental. O que desejamos lembrar é que esta é uma condição necessária mas não suficiente.

A mais urgente das reformas, na verdade náo depende de recursos financeiro. Fla é, contudo, condiçāo essencial para otimizar a aplicação desses recursos. Estamos falando do direito de cidadania garantido para toda população. Para que isso aconteça é fundamental reconstruir nossas instituições com base em valores democráticos. Essa reconstrução tem de passar pela reforma da justiça, pois só cla pode assegurar os direitos do cidadão e pela desprivatização do 
Estado, o que significa nos liberar de todo ranço patrimonialista.

\section{Resumen}

\section{DEMANDAS SOCIALES Y RECONSTRUCCIÓN DEL ESTADO}

Brasil ha vivido en un estado más o menos permanente de crisis, marcada por momentos de exacerbación, mezclados con otros momentos de relativa normalidad. La demanda por cambios es evidente. Una reflexión sobre la formación del listado brasileño y sobre su aparato politico y burocrático nos puede ayudar a entender los obstáculos que han impedido que el gobierno responda a las demandas sociales. La convivencia con dificulıades económicas y financieras, sim precedente en las últimas décadas, ha inducido a las autoridades a condicionar lo social a locconómico y financicro. La más ungente de las reformas es reconstruir nuestras instituciones, con base en valores verdaderamente democráticos, asegurando el derecho de ciudadanía a tocla la población.

\section{Abstract}

\section{SOCIAL DEMANDS AND REBUILDING THE STATE}

Brazil has been living in a sort of permanent crisis, marked by ixasperation with inttermittent periods of relative normality. 'The demand for changings is evident. A reflexion on the formation of the Brazilian State and it's political and bureaucratic apparatus can help us understand the obstacles that have constantly obstructed the government's response to social demands. Dealing with economic and financial dificulties, in a manner without precedents in the past two decades, has induced the authorities to condition the social to the economic and financial. The most urgent of the reforms is to rebuild our institutions, based on iruly democratic values, assuring the right to citizenship for the entire population.
Indiana Pinheiro Fonseca Rodrigues é coordenadora de mestrado da Faculdade de Ciências Económicas da Universidade Federal de Minas Gerais. 